\title{
Cellular and molecular events in early and mid gestation porcine implantation sites: a review
}

\author{
B.A. Croy', ', J.M. Wessels', N.F. Linton' M. van den Heuvel', \\ A.K. Edwards' and C. Tayade' \\ 'Department of Biomedical Sciences, Ontario Veterinary College, University of Cuelph, Guelph, ON, \\ N1C 2W1, Canada and 'Department of Anatomy and Cell Biology, Queen's University, Kingston, \\ ON, K7L 3N6, Canada
}

Commercial, North American pork breeds (Sus scrofa) experience significant loss of genetically-normal conceptuses during the peri-implantation (attachment) period and at mid-gestation (day 50 to 90 of the 114 day porcine gestation interval). Although exact causes for these losses are not defined, asynchronous in-utero development and deficits in vascularization of the endometrium and placenta appear to be involved. Understanding of normal maternal-fetal dialogue is critical to develop breeding or therapeutic strategies that improve fetal health and overall litter size in commercial pigs. The non-invasive, epitheliochorial porcine placenta permits investigation of maternal or fetal compartments without cross contaminating cells. We developed and use protocols to capture single, homogenous populations of porcine cells (endometrial lymphocytes, dendritic or endothelial cells) from histological sections using laser capture microdissection (LCM), a powerful tool for study of gene expression that reflects the in vivo environment. These data are compared with gene expression in biopsies of endometrium and of trophoblast from the same, attachment sites. Here we review justifications for selection of the genes we have studied and our published and in progress work. These data provide new insights into the roles of the endometrial immune environment in the regulation of the success and failure of porcine conceptuses.

\section{Introduction}

Prenatal mortality is a major economic concern for commercial swine producers in. North America. In gilts, approximately, 20 to $30 \%$ of conceptuses die between gestation days (gd) 12-30 and another $10-15 \%$ are lost by midgestation (114 day pregnancy, Pope et al. 1986, Pope 1988 , Pope 1994). The ovulation rate in these animals is 16 to 18 with $>95 \%$ fertilization. This should result in 14 to 17 embryos at the beginning of pregnancy. By farrowing however, litters are reduced to $\sim 10$ (Pope 1994). The pig uterus is estimated to have the capacity to carry 12 to 14 fetuses to term (Freking et al. 2007).

Conceptus-derived growth factors supplemented by histiotrophic nutrition derived from the maternal uterine glands (Spencer \& Bazer, 2004) support pre-elongation conceptuses. Growth and development of post-attachment ( $>$ gd15) conceptuses require endometrial-placental interactions that greatly expand local, through attachment site endometrial angiogenesis. Most 
porcine gestational losses occur as elongating conceptuses start secreting estrogen to promote endometrial attachment (Geisert et al. 1982). It is difficult to quantify losses of elongating conceptuses between gd 13 to 20 due to their extreme fragility (Pope 1994). Trophoblast-derived estrogen is considered to signal maternal recognition of pregnancy and alters the endometrium to support attachment (Geisert \& Yelich 1997). The estrogen secreted by the earliest elongating blastocysts creates a hostile endometrial milieu for less advanced conceptuses. Asynchronous development is a major factor influencing the first peri-attachment wave of conceptus loss (Pope 1994). A mixture of interferons (IFN) unique to porcine trophoblast is produced by early, peri-attachment embryos. Immune IFNG and IFND reach peak levels at gd15 (La Bonnardière et al. 1991, Cencic \& La Bonnardière 2002). Porcine trophoblastic IFNs, unlike IFNT in cattle and sheep, do not act on corpora lutea but alter polarity of the uterine epithelium through the gain of basal tight junctions during conceptus attachment (Cencic et al. 2003).

In other species, roles have been identified for the immune system in promotion of implantation and conceptus survival as well as in conceptus demise (Raghupathy 2001, Croy et al. 2006, Seavey \& Mosmann 2008). In humans, pregnancy success is associated with a switch from a type 1 dominant, pro-inflammatory cytokine profile the normal non pregnant state) to a type 2 dominant, anti-inflammatory profile in blood and in endometrium between mid to late pregnancy (Raghupathy 2001, Borzychowski et al. 2005, Aris et al. 2008).). Type 1 cytokine dominance in later gestation is considered to compromise pregnancy success (Raghupathy \& Kalinka 2008). As in humans and mice, early porcine pregnancy is dominated by pro-inflammatory type 1 cytokines such as IFN- $\gamma$ and TNF- $\alpha$ (Croy et al. 2006, Tayade et al. 2007, Curry et al. 2008). In addition to creating the endometrial cytokine milieu, the endometrial immune systems of humans and mice are strongly angiogenic in early gestation. The studies reviewed and reported here establish that immune cells of early porcine gestational endometrium make important, exquisitely localized contributions to conceptus attachment sites (CAS) that regulate conceptus fates.

\section{Transcripts for genes regulating angiogenesis in porcine endometrium and CAS}

\section{VECF and VECFR-mediated angiogenesis at porcine implantation sites}

Angiogenesis is the process of generation of new blood vessels from existing vasculature. It requires endothelial cell activation, tip cell differentiation, stalk cell proliferation and lumen formation. Maturation of new blood vessel is accompanied by recruitment of pericytes, smooth muscle cells and circulating bone-marrow derived cells (Takakura 2006, Grunewald et al. 2006). This is coupled with formation of an underlying basement membrane (Holderfield \& Hughes 2008). Extensive, localized endometrial angiogenesis occurs during pregnancy to support each developing conceptus and its placental exchange system.

Angiogenesis is regulated by variety of growth factors but VEGF and the VEGF receptor (R) system appear to be the most important and have been targeted clinically in humans (Loges et al. 2009). VEGFs are a family of heparin binding growth factors. In humans, at least eight VECF isoforms (VECF121, VECF145, VECF 148, VECF 165, VECF165b, VECF183, VECF189, and VECF206) are generated by alternative splicing of a single VEGF mRNA (Breen 2007). Similarly, eight VECF splice variants have been identified in pigs. Of these, splice variants, $V E G F_{12} 0,144,164,164 \mathrm{~b}, 188$ and 205 are exactly one amino acid shorter than the human variants while VECF 147 and 182 are unique porcine isoforms (Ribeiro et al. 2007). VEGF signals through VEGFRI, VEGFRII and VEGFR III and binds additionally to soluble VEGFRI (sVEGFRI), a splice variant of VEGFRI and to neuropilin-1 (NRP1). VEGFRI acts primarily as a regulator of VEGF availability (Holderfield \& Hughes 2008, Zygmunt et al. 2003). Soluble VEGFRI, which is elevated in human and mouse pregnancy complications (Levine et al. 2004), 
prevents VEGF signaling by sequestering VEGF (Zygmunt et al. 2003, Breen 2007). VEGF promotes migration of vascular smooth muscle cells through its binding to VEGFRI and to NPR1 (Banerjee et al. 2008). It induces endothelial cell migration and proliferation primarily through binding to VEGFRII (Holderfield \& Hughes 2008). VEGFRII is the dominant receptor promoting endothelial cell permeability. Placenta growth factor (PGF) is a high affinity ligand for VEGFR1 (Carmeliet 2001).

To understand the dynamic features of angiogenic gene expression at the porcine maternalfetal interface, mRNA comparisons for VECF, PCF, VECFRI and VEGFRII were carried out in various endometrial tissue microdomains and in endometrial biopsies and trophoblasts at gd20 and 50 from healthy conceptus attachment sites (H-CAS) and arresting conceptus attachment sites (A-CAS). Details of sample processing and techniques are summarized in Fig. 1 and are previously published (Tayade et al. 2006, 2007, Linton et al. 2008). Angiogenic gene profiles were studied by quantitative real time PCR analyses relative to housekeeping gene, ACTB ( $\beta$-actin). Transcripts for VEGF, PGF, VEGFRI and VEGFRII were detected in virgin uterus but their abundance differed between mesometrial and anti-mesometrial sides. In pregnancy, A-CAS at both gd20 and 50 had severely reduced numbers of VECF transcripts in endometrial biopsies compared with time-matched endometrium from H-CAS. VECF transcripts in trophoblast were relatively stable between $\mathrm{H}$-CAS and A-CAS. These differences suggested the maternal compartment had sensed "danger" signals emitted from individual conceptuses and was adjusting to promote demise of that conceptus while the conceptus maintained VECF transcription in its trophoblast for survival. Transcripts for VECFRI and II were variable between $\mathrm{H}-\mathrm{CAS}$ and A-CAS during both gd20 and 50 time points (Tayade et al. 2007).

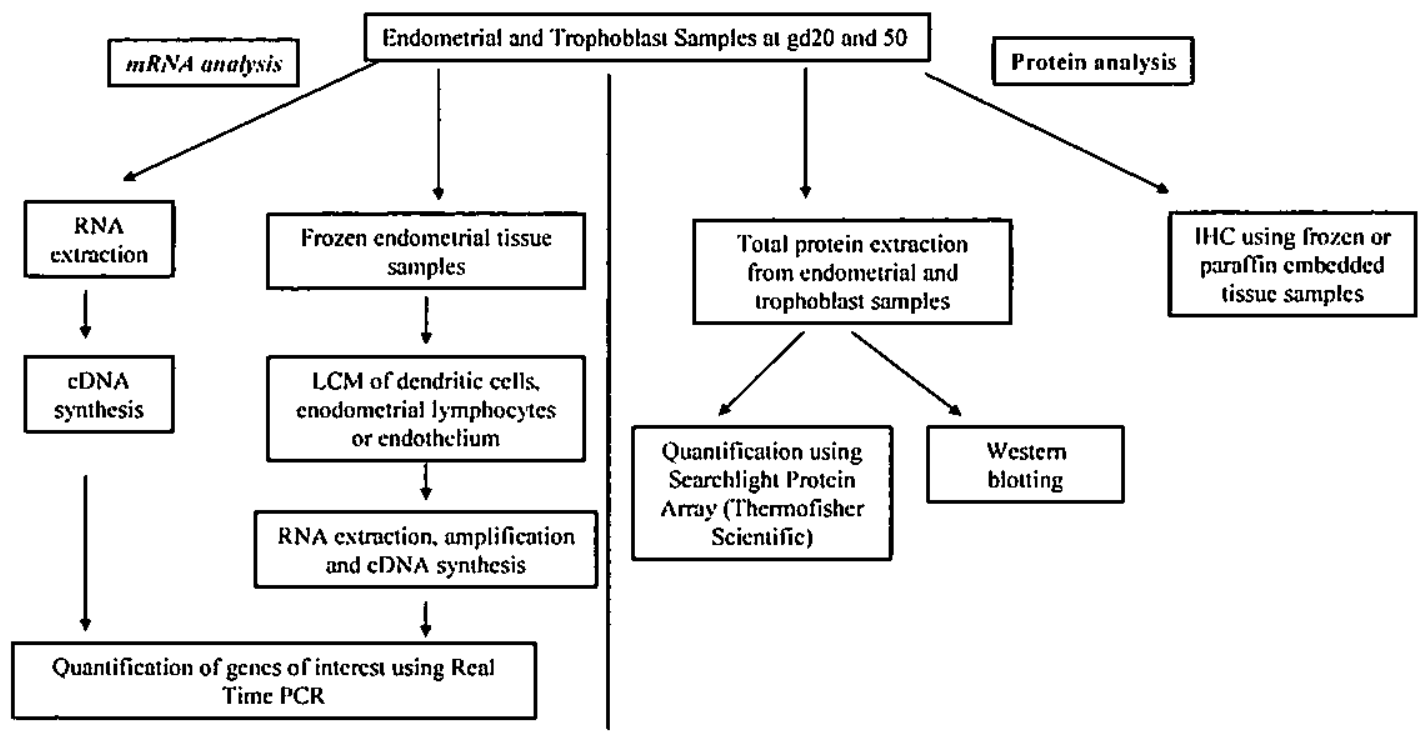

Fig. 1 Diagrammatic representation of sample utilization in various downstream applications. Each sample is processed either for mRNA or protein analysis as described in Tayade et al. 2006, 2007. All samples were collected from specific pathogen-free Yorkshire gilts housed at Arkell Swine Research Station, University of Guelph. Littermate H-CAS and A-CAS were identified based on gross fetal membrane vasculature at $\mathrm{gd} 20$ and length/weight parameters at gd50 (Tayade et al. 2006, 2007). The data were analyzed (unless otherwise stated) by PROC MIXED procedure of SAS using a mixed linear model that included the effects of gestation date, tissue, and health, as well as their interactions. 
Neuropilins, semaphorins and plexins in angiogenesis

The numerous VEGF isoforms bind endothelial cell receptors that include the VEGFRI and VEGFRII signaling tyrosine kinase receptors and the non-signaling co-receptor NRP1. NRP1 and NRP2 were identified in 1995 in the nervous system as receptors for class 3 semaphorins (SEMA) which repel axonal outgrowth (Satoda et al. 1995, He \& Tessier-Lavingne 1997, Kolodkin et al. 1997). They were subsequently found to act in endothelial cells as receptors for several pro-angiogenic factors, including VEGF ${ }_{165}$ (Soker et al. 1998), PGF (Soker et al.1998) hepatocyte growth factor (Sulpice et al. 2008), and galectin1 (Hsieh et al. 2008). Interestingly, NPR 1 as well as VEGF and VEGFRII are up-regulated on endothelial cells in hypoxic conditions (Ottino et al. 2004).

While NPR 1 and NPR2 are only $45 \%$ homologous, they are structurally similar with five extracellular domains, each of which has specific binding partners and a short cytoplasmic tail incapable of signal transduction. The $\mathrm{a} 1$ and $\mathrm{a} 2$ domains bind SEMAs. The b1 and b2 domains bind VEGF isoforms and heparin and are implicated in cell-cell adhesion. The c domain is responsible for dimerization. As shown in Table I, NPRs also differ in their VEGF and SEMA binding partners. NPRs themselves are non-signaling co-receptors which require complexing with receptors with signaling capability to effect downstream functions. NPR 1, which is expressed on endothelial cells, is associated with angiogenesis and arterial differentiation while NPR2, expressed in veins and lymphatic vessels, is involved in lymphangiogenesis (Karkkainen \& Alitalo 2002, Yuan et al. 2002).

Table I. Neuropilin (NRP) Interactions

\begin{tabular}{|c|c|c|c|c|}
\hline Gene & Pro-angiogenic Ligands & $\begin{array}{l}\text { Pro-angiogenic Complex } \\
\text { Partners }\end{array}$ & $\begin{array}{l}\text { Anti-angiogenic Complex } \\
\text { Partners }\end{array}$ & $\begin{array}{l}\text { Anti-angiogenic } \\
\text { ligands }\end{array}$ \\
\hline NRP1 & $\begin{array}{l}\text { VEGF165, VEGF-B, } \\
\text { VEGF-E, PGF, HGF, } \\
\text { PDGFBB, FGF2, TGF- } \beta \text {, } \\
\text { galectin1 }\end{array}$ & VEGFRI, VEGFRII, & $\begin{array}{l}\text { PLXNA1, PLXNA2, PLXNA3, } \\
\text { PLXNA4, PLXND1, integrin } \\
\text { B1, LICAM }\end{array}$ & $\begin{array}{l}\text { SEMA3A SEMA3B } \\
\text { SEMA3C SEMA3D }\end{array}$ \\
\hline NRP2 & $\begin{array}{l}\text { VEGF } 145 \text {, VEGF-C, } \\
\text { PGF, HGF }\end{array}$ & $\begin{array}{l}\text { VEGFRI, VEGFRII, } \\
\text { VEGFRIII, }\end{array}$ & $\begin{array}{l}\text { PLXNA1, PLXNA2, PLXNA3, } \\
\text { PLXNA4, PLXND1, NRCAM }\end{array}$ & $\begin{array}{l}\text { SEMA3C, SEMA3D } \\
\text { SEMA3F, SEMA3G }\end{array}$ \\
\hline
\end{tabular}

HGF: hepatocyte growth factor; LICAM: neural cell adhesion molecule L.1 (LICAM); NRCAM: neuronal cell adhesion molecule.

NPRs bind Class 3 SEMA, which are a large and diverse family with pivotal roles in axon guidance, organogenesis, neoplastic transformation, immune responses, vascularization and angiogenesis (Soker et al. 1998). SEMA functions through two receptor families; the NRPs and the plexins (PLXN). SEMA3s, a seven member family, are the only secreted semaphorins. Six SEMA3s bind to NRP1, NRP2 or both (see Table I). The seventh, SEMA3E, binds to the receptor plexin-D1, which in turn complexes with NRPs (Kolodkin et al. 1997). SEMA3A and SEMA3F bound by NRP and complexed with a plexin (PLXN) family member are anti-angiogenic because the complex suppresses endothelial cell migration (Guttmann-Raviv et al. 2007). Similarly, complexing NRPS and PLXN with SEMA3B and SEMA3F inhibited adhesion, migration and proliferation of lung cancer-derived tumor cells but the mechanism of these interactions is unknown. SEMA3A, SEMA3D, SEMA3E, and SEMA3G also have anti-tumorigenic properties and independently reduce the density of blood vessels in tumors (Neufeld \& Kessler 2008).

The roles of NRPs in blood vessel development during embryogenesis and tumour progression are well-studied. However, their roles in the only normal angiogenesis found in adults, the cycling female reproductive tract, have not been thoroughly addressed. Pavelock et al. found that physiological variations in different sex hormones, particularly progesterone, increased 
NPR1 mRNA in rat uterus (Pavelock et al. 2001). These data gave us the impetus to quantify expression of NPRs and their binding and complexing partners in the virgin and pregnant porcine uterus. Transcripts of NPR 1 and NPR2, SEMA-A $3 C 3, E 3, F 3$ and $C 3$ as well as PLXN $A 1, A 2, A 3, A 4$ and $D 1$ were detected in the virgin pig uterus as well as in endometrial and trophoblast samples at gd20 and 50. Quantification of these genes is in progress ( $M$ van den Heuvel, unpublished observations).

Lymphocytes and dendritic cells in the promotion of endometrial angiogenesis during pregnancy

We found porcine endometrium of early pregnancy contained mildly elevated $(-3 x)$ numbers of uterine natural killer (uNK) cells, a unique lymphocyte subset, between gd 15 to 28 . During pregnancy, these cells were found scattered throughout the stroma, beneath luminal epithelium, around blood vessels and uterine glands (Engelhardt et al. 2002). This interval coincides with onset of angiogenesis at CAS. In contrast to the recruitment of uNK cells in humans and mice that is driven by decidual cells, porcine UNK cells were not recruited in pseudopregnancy but required conceptus-derived signals that are not yet identified (Engelhardt et al. 2002). Porcine uNK cells are agranular and their identification required dual antibody staining against CD16 and CD8 surface receptors to distinguish them from T cells. Recently, Dimova et al. (2007) examined changes in endometrial T cells (CD4 and CD8) during early porcine pregnancy. T-cells formed clusters in areas of conceptus attachment but no significant differences were found in their numbers at or between CAS. T lymphocytes increased in the sub-epithelium from 15\% of leukocytes in the pre-attachment phase to $54 \%$ right after attachment at gd15. Maximal T lymphocyte numbers reached $85 \%$ at gd 30 after the formation of placenta (Dimova et al. 2007). In our studies, we noticed scattered lymphocytes in the luminal epithelium but due to lack of commercially available porcine specific monoclonal antibodies, phenotypic characterization of the intra-epithelial lymphocytes could not be carried out. Thus, our studies of gene expression in endometrial lymphocytes have not yet been refined to address lineage subsets. We employ frozen endometrial tissue sections rapidly stained with haematoxylin and eosin and laser capture microdissection (LCM) to collect pure populations of either lymphocytes or dendritic cells (DC; Tayade et al. 2006, Linton et al. 2008) to address our hypothesis that immune cells contribute to and regulate endometrial angiogenesis during porcine pregnancy.

Endometrial lymphocytes obtained from healthy and arresting conceptus attachment sites at gd20 and gd50 were screened for the expression of VECF, PCF, VECFRI and VECFRII by quantitative real time PCR. Endometrial lymphocytes had a much greater abundance of VECF transcripts than endometrial endothelial cells or trophoblasts. Attachment sites associated with arresting conceptuses had a severe reduction in VECF and gain in PCF transcripts in lymphocytes. Lymphocytes preferentially expressed transcripts for VEGFRI whereas trophoblasts had abundant VECFRII transcripts showing there are differences in the mechanisms that regulate angiogenesis in the maternal and fetal compartments (Tayade et al. 2007).

In humans, a population of immature dendritic cells was identified in decidua via their surface expression of DC-SICN (Dendritic cell specific ICAM grabbing non-integrin, DC-SIGN) (Kammerer et al. 2003,2008). These antigen presenting cells were in contact with uNK cells in the vicinity of spiral arteries, an interaction requiring DC-SIGN on the DCs and ICAM-3 on the uNK cells (Kammerer et al. 2003). Because UNK cells secrete abundant VEGF but do not express VEGFRI or II (Li et al. 2001), we hypothesize that endometrial DC-SIGN+ DCs and uNK cells may additionally communicate via VEGF and its receptors. This would also predict perivascular co-localization of these cell types to sites of active endothelial cell proliferation (Grunewald et al. 2006). Using a cross-reactive anti-human DC-SIGN antibody, we identified DC-SIGN + DCS 
in porcine endometrium. In contrast to human endometrium where the cells are only present in pregnancy, both virgin and gestational porcine endometrium contained DC-SIGN + cells (Linton et al. 2008). In pregnancy, DC-SICN + cells were frequently associated with lymphocytes near blood vessels. The numbers of DC-SIGN + cells appeared to be stable between early and mid pregnancy. Using a modified immunohistochemistry protocol for rapid staining, we immunostained DC-SIGN + DCs in frozen porcine endometrial sections, isolated them using LCM and recovered RNA for analysis. We report for the first time that porcine DC-SIGN + DCs transcribe angiogenic factors (VECF, VECFRI and II) and thus contribute to the regulation of angiogenesis at CAS (Linton et al. 2008 and N F Linton, unpublished observations).

\section{Roles of chemokines and chemokine decoy receptors at the porcine maternal fetal interface}

Chemokines are families of small cytokines characterized by the presence of four conserved cysteine molecules. They range from 8 to $11 \mathrm{kDa}$ and are active over a 1 to $100 \mathrm{ng} / \mathrm{ml}$ range in concentration. The major function of chemokines is to direct immune cell movement towards chemotactic stimuli (Charo \& Ransohoff 2006). Chemokines are classified as CC, CXC, CX3C or XC (Charo \& Ransohoff 2006). Almost all somatic cell types synthesize pro-inflammatory as well as homeostatic chemokines. Chemokines can be induced by variety of stimuli including viruses, bacteria, pro-inflammatory cytokines, anaphylatoxin $\mathrm{C} 5 \mathrm{a}$, leukotriene $\mathrm{B}_{4^{\prime}}$ and IFNs (Drake et al. 2002, Huang et al. 2006). Although their main function is chemo-attraction, they also participate in angiogenesis, haematopoiesis, and regulate activation, proliferation, differentiation, and apoptosis in the cells they attract (Drake et al. 2002, Hannan et al. 2006).

Chemokine decoy receptors are non-signaling, membrane-bound receptors. They are responsible for regulation of cell trafficking, inflammatory responses, immune reactions, angiogenesis, and apoptosis by internalizing and degrading chemokines (Mantovani et al. 2001, Mantovani et al. 2003, Borroni et al. 2008). In humans and mice, three chemokine decoy receptors have been characterized. D6 and DARC (duffy antigen receptor for chemokines) bind inflammatory chemokines while CCX CKR binds homeostatic chemokines (Cosling et al. 2000, Townson \& Nibbs 2002). In humans and mice, D6 is expressed by invasive trophoblast cells (Montavani et al. 2003, Martinez de la Torre et al. 2007). D6 knockout mice are fertile but have compromised pregnancy outcome if inoculated with lipopolysaccharide or auto-immune human anti-phospholipid antibodies during pregnancy (Martinez de la Torre et al. 2007). DARC and CCX CKR are also found in human and mouse placentas (Girard et al. 1999, Townson \& Nibbs 2002, Martinez de la Torre et al. 2007). However, roles for decoy receptors and their binding chemokines have not been characterized in spontaneous fetal loss or in pregnancies with non invasive trophoblast. We have investigated selected members of these molecular families that are expected in porcine pregnancy.

Transcripts for chemokines that expected to bind to porcine D6 (CCL2, CCL3L1, CCL4, CCL5 and CCL11), DARC (CCL2, CCL5, CCL11 and CXCL2) or CCX CKR (CCL21) were assessed in paired gd20 and 50 endometrial and trophoblast samples from H-CAS and A-CAS. Transcripts were found for all of the genes in gd20 and gd50 endometrium and trophoblast. No significant differences were found in the expression of these chemokines between healthy and arresting conceptus attachment sites (Wessesl et al. 2007 and ) M Wessels, unpublished observations).

Endometrial transcripts for D6 were more abundant than those in trophoblast at gd20 and 50. Transcript numbers were stable at healthy versus arresting sites. In contrast, transcripts for the homeostatic decoy receptor $C C X C K R$ were elevated in gd50 trophoblasts and endometrium 
from A-CAS O M Wessels, unpublished observations). Both molecules were localized by immunohistochemistry to uterine epithelium at the CAS. Thus, the importance of inflammation in gestational failure in pigs appears to be much less than in mice while dysregulation of porcine homeostasis may have a greater role in both maternal and fetal tissues. The role of homeostatic chemokines decoy receptors in pregnancy failure or success in other species has not been studied yet. Thus, the relevance of these findings for species with non epitheliochorial placentation is currently unknown and needs to be defined.

\section{Role of pro-inflammatory cytokines at the porcine maternal fetal interface}

The adverse effects of elevated pro-inflammatory cytokines during human and mouse pregnancy are extensively studied (Polgar \& Hill 2002, Dent 2002, Patrick \& Smith 2002). Several reports linked TNFA, combined with IFNG and IL-1B in promoting pathology and pregnancy failure. In women with recurrent spontaneous abortions, synergistic effects of TNFA and IFNG lead to endothelial cell injury, reduced blood supply and subsequent embryonic death (Stemmer 2000). In addition to the deficits in endometrial angiogenesis described above at porcine A-CAS, we have documented elevations in proinflammatory cytokine gene transcripts (IFNC, TNFA and $(L-1 B)$. Endometrial lymphocytes appeared to switch transcription abruptly from angiogenic to pro-inflammatory cytokine genes.

Based on these findings we proposed paradigm shifting functions for endometrial lymphocytes (Leonard et al. 2006). We feel the elevated pro-inflammatory cytokines attack maternal endothelial cells ultimately restricting blood supply to an already stressed conceptus rather than envisioning trophoblast as the target of immune attack. This raises the possibility that elevations in pro-inflammatory cytokines are an aftermath of impending conceptus death. In pigs, this immune signaling is unlikely to be an immune scavenging signal because we did not observe signs of inflammation (infiltration of neutrophils/lymphocytes) at A-CAS at gd20 or 50 . Definition of this cause and effect relationship will require further study. We found significantly elevated expression of IFNC in endometrial lymphocytes and trophoblasts collected from gd20 A-CAS but not in gd50 A-CAS. Rather, TNFA was elevated in lymphocytes obtained from gd50 A-CAS. The dominance of IFNC during early loss (gd20) and TNFA during mid gestational loss (gd50) suggests distinct immune mechanisms effect conceptus health at different stages of gestation (Tayade et al. 2007).

\section{Insulin like growth factors 1 and 2 in porcine fetal loss}

Insulin like growth factors (IGF-1 and IGF-2) are small polypeptides of approximately $7 k D a$ implicated in regulation of fetal and placental growth. They promote cellular differentiation, proliferation and migration and inhibit apoptosis. These processes are involved in the extensive remodeling that occurs during development of the placenta and its endometrial attachment site. The IGFs bind with high affinity to IGF receptors, namely IGF IR and IGF2R. IGF IR is a member of the tyrosine kinase family and is structurally related to the insulin receptor Uones \& Clemmons 1995, Butler \& LeRoith 2001). IGF1R binds with equal affinity to both IGF-1 and IGF-2, where as IGF2R binds only IGF-2 with high affinity (Pollak 2008). The bio-availability and biological actions of IGFs are regulated by at least six insulin-like growth factor binding proteins (IGFBP1 to 6, Clemmons 1997). IGF ligation to binding proteins may augment or inhibit IGF action. Several proteases cleave IGFBPs, reducing or eliminating their ability to bind IGFs. From a series of knockout studies, it is clear that IGF 2 rather than IGF 1 plays important roles in mouse placental and fetal development (Baker et al. 1993). 
The IGF system has been extensively studied during the porcine estrous cycle and in early pregnancy (Simmen et al. 1992, Ashworth et al. 2005). ICF-1 mRNA decreased while IGF-2 mRNA increased as pregnancy advanced. Highest levels were found in the placenta followed by endometrium and myometrium (Simmen et al. 1992). There is a spatiotemporal relationship between increased uterine IGF- 1 and IGF-2 and estrogen synthesis by the elongating conceptuses at gd10 to 13 (Letcher et al. 1989, Geisert et al. 2001). Increased uterine IGF is associated with aromatase production for trophoblast estrogen synthesis (Green et al. 1995). Ashworth et al. (2005), documented premature loss of IGFs during the period of conceptus elongation by early exposure of pregnant gilts to estrogen. This loss of IGFs was attributed to proteolysis of IGFBPs due to endocrine disruption caused by exogenous administration of estrogen at the time of conceptus elongation (Ashworth et al. 2005).

We addressed whether IGF- 1 and 2 are directly linked with porcine conceptus arrest at gd20 and 50. Transcripts for $I C F-1$ and $/ C F-2$ were quantified in trophoblast and endometrial biopsies at gd20 and gd50 by real time PCR and expressed as a ratio of target gene (ICF) to ACTB (Fig. $2 \mathrm{~A}$ and $\mathrm{B}$ ). At gd20, trophoblast from A-CAS had fewer $/ G F-1$ transcripts than trophoblast from $\mathrm{H}$-CAS. At gd50, trophoblasts had more transcripts than gd50 endometrial samples $(P<0.05)$. In gd20 endometrial samples (Fig. 2A), IGF-1 was more abundant than in gd50 endometrium $(P<0.05)$. These data are consistent with other reports that $/ G F-1$ declines as pregnancy advances (Simmen et al. 1992, Ashworth et al. 2005). ICF-2 transcripts were 10-fold higher in both endometrial and trophoblast samples than $/ C F-1$ transcripts. No significant differences were found in either tissue at gd20 or gd50 related to conceptus health status. Our results are in agreement with previous reports that ICF-2 is predominantly expressed over ICF-1 during porcine pregnancy (Simmen et al. 1992). Our studies did not provide any evidence that IGFs are directly linked with porcine fetal arrest. More comprehensive studies that includes IGF receptors and IGFBPs are in progress.

\section{Final remarks}

Our molecular interrogation of endometrial attachment sites of live fetal littermates whose gestational fates differ, has identified clear roles for immune cells, both lymphoid and dendritic, in promotion of endometrial angiogenesis within CAS. Coincident with conceptus arrest, changes occur in the immune system that could have primary and/or secondary roles in the death of specific fetuses. The immune system appears to respond to fetal distress by removing vascular support for that CAS and locally elevating pro-inflammatory cytokines. These changes may be induced in resident cells because no significant alterations were found in chemokines ligands binding to pro-inflammatory decoy receptors or in the decoy receptor D6 between $\mathrm{H}$-CAS and A-CAS. Alterations in expression of the homeostatic decoy receptor CCX-CKR between $\mathrm{H}$-CAS and A-CAS suggest a new regulatory pathway that may contribute to porcine pregnancy success.

\section{Acknowledgements}

This research was supported by Ontario Pork, OMAFRA, NSERC, Agriculture and Agrifood Canada and the Canada Research Chairs Program. 
A
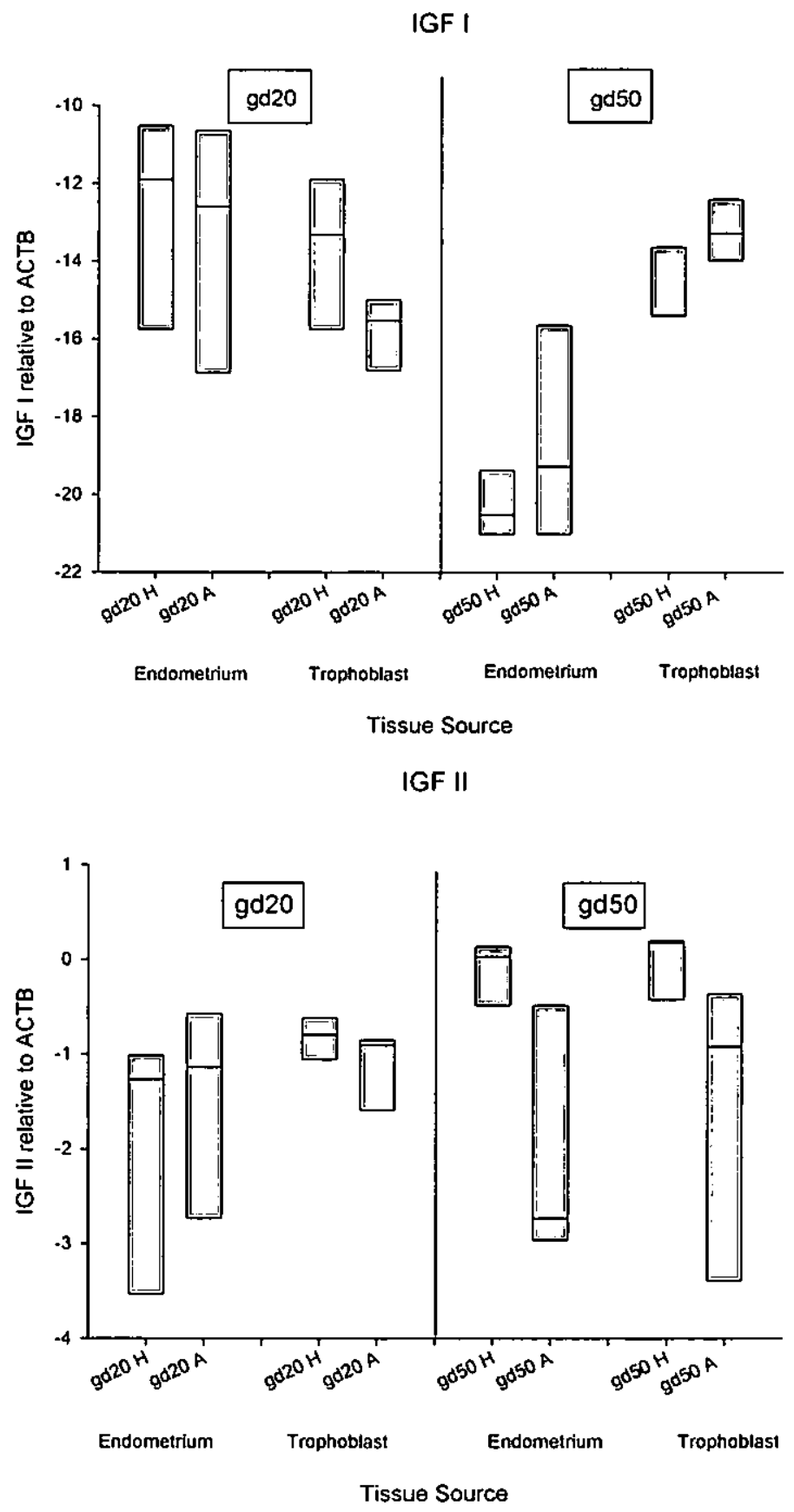

Fig. 2 Expression of $/ C F 1(\mathrm{~A})$ and $/ C F 2(\mathrm{~B})$ in porcine endomerium and trophoblasts at gd 20 and 50. Expression was quantified by real time PCR using RelQuant software (Roche) and is relative to the housekeeping gene, ACTB. The LightCycler program was denaturation at $94^{\circ} \mathrm{C}, 15 \mathrm{~min} ; \mathrm{PCR}$ amplification and quantification $\left(95^{\circ} \mathrm{C}, 10 \mathrm{~s} ; 58^{\circ} \mathrm{C}, 5 \mathrm{~s} ; 72^{\circ} \mathrm{C}, 20 \mathrm{~s}\right)$ with the fluorescence measurement at specific acquisition temperatures for $5 \mathrm{~s}$, repeated for 45 cycles. Statistical analysis was performed using one way ANOVA and pair-wise multiple comparison procedure as per Holm-Sidak method. The bar in each box represents the data median with 6 samples per group. $P<0.05$ was considered significant. gd: gestation days, $\mathrm{H}$ : healthy, A: arresting. 


\section{References}

Aris A, Lambert F, Bessette P \& Moutquin JM 2008 Maternal circulating interferon-gamma and interleukin- 6 as biomarkers of Th $1 / \mathrm{Th} 2$ immune status throughout pregnancy. The Journal of Obstetrics and Gynaecology Research 34 7-11.

Ashworth MD, Ross IW, Stein DR, Allen DT, Spicer LJ \& Geisert RD 2005 Endocrine disruption of uterine insulin-like growth factor expression in the pregnant gilt. Reproduction 130 545-551.

Baker J, Liu JP, Robertson EJ \& Efstratiadis A 1993 Role of insulin-like growth factors in embryonic and postnatal growth. Cell 75 73-82.

Banerjee S, Mehta S, Haque I, Sengupta K, Dhar K, Kambhampati $S$, Van Veldhuizen Pf \& Banerjee SK 2008 VEGF-A165 induces human aortic smooth muscle cell migration by activating neuropilin-1VEGFR1-PI3K axis. Biochemistry 47 3345-3351.

Borroni EM, Bonecchi R, Buracchi C, Savino B, Mantovani A \& Locati M 2008 Chemokine decoy receptors: new players in reproductive immunology. Immunological investigations 37 483-497.

Borzychowski AM, Croy BA, Chan WL, Redman CW \& Sargent IL 2005 Changes in systemic type 1 and type 2 immunity in normal pregnancy and pre-eclampsia may be mediated by natural killer cells. European Journal of Immunology 35 3054-3063.

Breen EC 2007 VEGF in biological control. fournal of Cellular Biochemistry 102 1358-1367.

Butler AA \&LeRoith D 2001 Minireview: tissue-specific versus generalized gene targeting of the IGF 1 and IGF $1 \mathrm{r}$ genes and their roles in insulin-like growth factor physiology. Endocrinology 142 1685-1688.

Carmeliet $P$, Moons L, Luttun A, Vincenti V, Compernolle V, De Mol M, Wu Y, Bono F, Devy L, Beck H, Scholz D, Acker T, DiPalma T, Dewerchin M, Noel A, Stalmans I, Barra A, Blacher S, Vandendriessche T, Ponten A, Eriksson U, Plate KH, Foidart JM, Schaper W, Charnock-Jones DS, Hicklin D), Herbert JM, Collen D \& Persico MG 2001 Synergism between vascular endothelial growth factor and placental growth factor contributes to angiogenesis and plasma extravasation in pathological conditions. Nature Medicine 7 575-583.

Cencic A, Guillomot $M$, Koren S \& La Bonnardiere C 2003 Trophoblastic interferons: do they modulate uterine cellular markers at the time of conceptus attachment in the pig? Placenta 24 862-869.

Cencic A \& La Bonnardiere C 2002 Trophoblastic interferon-gamma: current knowledge and possible role(s) in early pig pregnancy. Veterinary Research 33 139-157.

Charo IF \&Ransohoff RM 2006 The many roles of chemokines and chemokine receptors in inflammation. The New England Journal of Medicine 354 610-621.

Clemmons DR 1997 Insulin-like growth factor binding proteins and their role in controlling IGF actions. Cytokine \& Growth Factor Reviews 8 45-62.

Croy BA, van den Heuvel MJ, Borzychowski AM \& Tayade C 2006 Uterine natural killer cells: a specialized differentiation regulated by ovarian hormones. Immunological reviews 214 161-185.

Curry AE, Vogel I, Skogstrand K, Drews C, Schendel DE, Flanders WD, Hougaard DM \& Thorsen P 2008 Maternal plasma cytokines in early-and mid-gestation of normal human pregnancy and their association with maternal factors. Journal of Reproductive Immunology 77 152-160.

Dent LA 2002 For better or worse: common determinants influencing health and disease in parasitic infections, asthma and reproductive biology. Journal of Reproductive Immunology 57 255-272.

Dimova T, Mihaylova A, Spassova P \& Georgieva R 2007 Establishment of the porcine epitheliochorial placenta is associated with endometrial T-cell recruitment. American Journal of Reproductive Immunology 57 250-261.

Drake PM, Red-Horse K \& Fisher S] 2002 Chemokine expression and function at the human maternal-fetal interface. Reviews in Endocrine \& Metabolic Disorders 3 159-165.

Engelhardt H, Croy BA \& King G) 2002 Evaluation of natural killer cell recruitment to embryonic attachment sites during early porcine pregnancy. Biology of Reproduction 66 1185-1192.

Freking BA, Leymaster KA, Vallet IL \& Christenson RK 2007 Number of fetuses and conceptus growth throughout gestation in lines of pigs selected for ovulation rate or uterine capacity. Journal of Animal Science 85 2093-2103.

Geisert RD, Chamberlain CS, Vonnahme KA, Malayer JR \& Spicer LJ 2001 Possible role of kallikrein in proteolysis of insulin-like growth factor binding proteins during the oestrous cycle and early pregnancy in pigs. Reproduction 121 719-728.

Geisert RD, Renegar RH, Thatcher WW, Roberts RM \& Bazer FW 1982 Establishment of pregnancy in the pig: I. Interrelationships between preimplantation development of the pig blastocyst and uterine endometrial secretions. Biology of Reproduction 27 925-939.

Geisert RD \&Yelich IV 1997 Regulation of conceptus development and attachment in pigs. Journal of Reproduction and Fertility Supplement 52 133-149.

Girard JP, Baekkevold ES, Yamanaka T, Haraldsen G, Brandtzaeg P \& Amalric F 1999 Heterogeneity of endothelial cells: the specialized phenotype of human high endothelial venules characterized by suppression subtractive hybridization. The American Journal of Pathology 155 2043-2055.

Green ML, Simmen RC \& Simmen FA 1995 Developmental regulation of steroidogenic enzyme gene expression in the periimplantation porcine conceptus: a paracrine role for insulin-like growth factor-I. Endocrinology 136 3961-3970.

Gosling J, Dairaghi DJ, Wang Y, Hanley M, Talbot D, Miao Z \& Schall TJ 2000 Cutting edge: identification of a novel chemokine receptor that binds dendritic celland T cell-active chemokines including ELC, SLC, and 
TECK. Journal of immunology 164 2851-2856.

Grunewald M, Avraham I, Dor Y, Bachar-Lustig E, Itin A, Jung S, Chimenti S, Landsman L, Abramovitch R \& Keshet $E 2006$ VEGF-induced adult neovascularization: recruitment, retention, and role of accessory cells. Cell 124 175-189.

Guttmann-Raviv N, Shraga-Heled N, Varshavsky A, Guimaraes-Sternberg C, Kessler O \& Neufeld G 2007 Semaphorin-3A and semaphorin-3F work together to repel endothelial cells and to inhibit their survival by induction of apoptosis. The lournal of Biological Chemistry 282 26294-26305.

Hannan N\}, Jones RL, White CA \& Salamonsen LA 2006 The chemokines, $\mathrm{CX} 3 \mathrm{CL} .1, \mathrm{CCL} 14$, and $\mathrm{CCL} 4$, promote human trophoblast migration at the feto-maternal interface. Biology of Reproduction 74 896-904.

He Z \& Tessier-Lavigne M 1997 Neuropilin is a receptor for the axonal chemorepellent Semaphorin III. Cell 90 739-751.

Holderfield MT \&Hughes CC 2008 Crosstalk between vascular endothelial growth factor, notch, and transforming growth factor-beta in vascular morphogenesis. Circulation Research 102 637-652.

Hsieh SH, Ying NW, Wu MH, Chiang WF, Hsu CL, Wong TY, Jin YT, Hong TM \& Chen YL 2008 Galectin-1, a novel ligand of neuropilin-1, activates VECFR-2 signaling and modulates the migration of vascular endothelial cells. Oncogene 27 3746-3753.

Huang SI, Schatz F, Masch R, Rahman M, Buchwalder L, Niven-Fairchild T, Tang C, Abrahams VM, Krikun G \& Lockwood CJ 2006 Regulation of chemokine production in response to pro-inflammatory cytokines in first trimester decidual cells. Journal of Reproductive Immunology 72 60-73.

Jones II \&Clemmons DR 1995 Insulin-like growth factors and their binding proteins: biological actions. Endocrine Reviews 16 3-34.

Kammerer U, Eggert AO, Kapp M, McLellan AD, Geijtenbeek TB, Dietl I, van Kooyk $Y$ \& Kampgen E 2003 Unique appearance of proliferating antigenpresenting cells expressing DC-SIGN (CD209) in the decidua of early human pregnancy. The American journal of Pathology 162 887-896.

Kammerer U, Kruse A, Barrientos G, Arck PC \& Blois SM 2008 Role of dendritic cells in the regulation of maternal immune responses to the fetus during mammalian gestation. Immunological investigations 37 499-533.

Karkkainen MJ \&Alitalo K 2002 Lymphatic endothelial regulation, lymphoedema, and lymph node metastasis. Seminars in Cell \& Developmental Biology 13 9-18.

Kolodkin AL, Levengood DV, Rowe EG, Tai YT, Giger RJ \& Ginty DD 1997 Neuropilin is a semaphorin III receptor. Cell 90 753-762.

La Bonnardiere C, Martinat-Botte F, Terqui M, Lefevre F, Zouari K, Martal | \& Bazer FW 1991 Production of two species of interferon by Large White and Meishan pig conceptuses during the peri-attachment period. Journal of Reproduction and fertility 91 469-478.

Leonard S, Murrant C, Tayade $C$, van den Heuvel $M$, Watering R \& Croy BA 2006 Mechanisms regulating immune cell contributions to spiral artery modification -- facts and hypotheses - a review. Placenta 27 Supplement A S40-6.

Letcher R, Simmen RC, Bazer FW \& Simmen FA 1989 Insulin-like growth factor-I expression during early conceptus development in the pig. Biology of Reproduction 41 1143-1151.

Levine R], Maynard SE, Qian C, Lim KH, England L\}, Yu KF, Schisterman EF, Thadhani R, Sachs BP, Epstein FH, Sibai BM, Sukhatme VP \& Karumanchi SA 2004 Circulating angiogenic factors and the risk of preeclampsia. The New England lournal of Medicine 350 672-683.

Li XF, Charnock-Jones DS, Zhang E, Hiby S, Malik S, Day $K$, Licence D, Bowen IM, Gardner L, King A, Loke YW \& Smith SK 2001 Angiogenic growth factor messenger ribonucleic acids in uterine natural killer cells. The Journal of Clinical Endocrinology and Metabolism 86 1823-1834.

Linton NF, Wessels JM, Cnossen SA, Croy BA \& Tayade C 2008 Immunological mechanisms affecting angiogenesis and their relation to porcine pregnancy success. Immunological Investigations 37 611-629.

Loges S, Roncal C \& Carmeliet P 2009 Development of targeted angiogenic medicine. fournal of Thrombosis \& Haemostasis 7 21-33.

Mantovani A, Bonecchi R, Martinez FO, Galliera E, Perrier P, Allavena P \& Locati M 2003 Tuning of innate immunity and polarized responses by decoy receptors. International Archives of Allergy and Immunology 132 109-115.

Mantovani A, Locati M, Vecchi A, Sozzani S \& Allavena P 2001 Decoy receptors: a strategy to regulate inflammatory cytokines and chemokines. Trends in Immunology 22 328-336.

Martinez de la Torre $Y$, Buracchi C, Borroni EM, Dupor J, Bonecchi R, Nebuloni M, Pasqualini F, Doni A, Lauri E, Agostinis C, Bulla R, Cook DN, Haribabu B, Meroni P, Rukavina D, Vago L, Tedesco F, Vecchi A, Lira SA, Locati M \& Mantovani A 2007 Protection against inflammation- and autoantibody-caused fetal loss by the chemokine decoy receptor D6. Proceedings of the National Academy of Sciences of the United States of America 104 2319-2324.

Neufeld G \& Kessler O 2008 The semaphorins: versatile regulators of tumour progression and tumour angiogenesis. Nature Reviews Cancer 8 632-645.

Oltino P, Finley J, Rojo E, Ottlecz A, Lambrou GN, Bazan HE \& Bazan NG 2004 Hypoxia activates matrix metalloproteinase expression and the VECF system in monkey choroid-retinal endothelial cells: Involvement of cytosolic phospholipase A2 activity. Molecular Vision 10 341-350.

Patrick LA \& Smith GN 2002 Proinflammatory cytokines: a link between chorioamnionitis and fetal brain injury. lournal of Obstetrics and Cynaecology Canada 24 705-709.

Pavelock K, Braas K, Ouafik L, Osol C \& May V 2001 Differential expression and regulation of the vascular endothelial growth factor receptors neuropilin-1 and neuropilin-2 in rat uterus. Endocrinology 142 613-622. 
Polgar K \& Hill JA 2002 Identification of the white blood cell populations responsible for Th 1 immunity to trophoblast and the timing of the response in women with recurrent pregnancy loss. Gynecologic and Obstetric Investigation 53 59-64.

Pollak M 2008 Insulin and insulin-like growth factor signalling in neoplasia. Nature Reviews Cancer $\mathbf{8}$ 915-928.

Pope WF 1988 Uterine asynchrony: a cause of embryonic loss. Biology of Reproduction 39 999-1003.

Pope WF, Lawyer MS, Nara BS \& First NL 1986 Effect of asynchronous superinduction on embryo survival and range of blastocyst development in swine. Biology of Reproduction 35 133-137.

Pope WF 1994 Embryonic mortality in swine. In Embryonic Mortality in Domestic Species pp 53-78. Ed. Geisert RD, Zavy MT. CRC Press Inc. Boca Raton.

Raghupathy R 2001 Pregnancy: success and failure within the Th $1 / \mathrm{Th} 2 / \mathrm{Th} 3$ paradigm. Seminars in /mmunology 13 219-227.

Raghupathy R \& Kalinka J 2008 Cytokine imbalance in pregnancy complications and its modulation. Frontiers in Bioscience 13 985-994.

Ribeiro LA, Bacci ML, Seren E, Tamanini C \& Forni M 2007 Characterization and differential expression of vascular endothelial growth factor isoforms and receptors in swine corpus luteum throughout estrous cycle. Molecular Reproduction and Development 74 163-171.

Satoda $M$, Takagi S, Ohta K, Hirata T \& Fujisawa H 1995 Differential expression of two cell surface proteins, neuropilin and plexin, in Xenopus olfactory axon subclasses. The Journal of Neuroscience 15 942-955.

Seavey MM \& Mosmann TR 2008 immunoregulation of fetal and anti-paternal immune responses. Immunologic Research 40 97-113.

Simmen FA, Simmen RC, Geisert RD, Martinat-Botte F, Bazer FW \& Terqui M 1992 Differential expression, during the estrous cycle and pre- and postimplantation conceptus development, of messenger ribonucleic acids encoding components of the pig uterine insulin-like growth factor system. Endocrinology 130 1547-1556.
Soker S, Takashima S, Miao HQ, Neufeld G \& Klagsbrun M 1998 Neuropilin-1 is expressed by endothelial and Iumor cells as an isoform-specific receptor for vascular endothelial growth factor. Cell 92 735-745.

Spencer TE \& Bazer FW 2004 Uterine and placental factors regulating conceptus growth in domestic animals. Journal of Animal Science 82 E-Suppl E4-13.

Stemmer SM 2000 Current clinical progress in early pregnancy investigation. Early Pregnancy (Online) $474-81$.

Sulpice E, Plouet 1, Berge M, Allanic D, Tobelem G \& Merkulova-Rainon T 2008 Neuropilin-1 and neuropilin-2 act as coreceptors, potentiating proangiogenic activity. Blood 111 2036-2045.

Takakura N 2006 Role of hematopoietic lineage cells as accessory components in blood vessel formation. Cancer Science 97 568-574.

Tayade C, Black GP, Fang Y \& Croy BA 2006 Differential gene expression in endometrium, endometrial lymphocytes, and trophoblasts during successful and abortive embryo implantation. Journal of Immunology 176 148-156.

Tayade C, Fang Y, Hilchie D \& Croy BA 2007 Lymphocyte contributions to altered endometrial angiogenesis during early and midgestation fetal loss. Journal of Leukocyte Biology 82 877-886.

Townson JR \& Nibbs RJ 2002 Characterization of mouse CCX-CKR, a receptor for the lymphocyte-attracting chemokines TECK/mCCL25, SLC/mCCL21 and MIP. 3 beta/mCCL.19: comparison to human CCX-CKR. European lournal of Immunology 32 1230-1241.

Wessels IM, Linton NF, Croy BA \& Tayade C 2007 A review of molecular contrasts between arresting and viable porcine attachment sites. American Journal of Reproductive Immunology 58 470-480.

Yuan L, Moyon D, Pardanaud L, Breant C, Karkkainen M), Alitalo K \& Eichmann A 2002 Abnormal lymphatic vessel development in neuropilin 2 mutant mice. Development 129 4797-4806.

Zygmunt $M$, Herr F, Munstedt K, Lang U \& Liang OD 2003 Angiogenesis and vasculogenesis in pregnancy. European journal of Obstetrics, Cynecology and Reproductive Biology 110 Suppl 1 510-8. 